\title{
Growth and Flowering Responses of Cut Chrysanthemum Grown under Restricted Root Volume to Irrigation Frequency
}

\author{
Viyachai Taweesak, ${ }^{1}$ Thohirah Lee Abdullah, ${ }^{1}$ Siti Aishah Hassan, ${ }^{1}$ \\ Nitty Hirawaty Kamarulzaman, ${ }^{2}$ and Wan Abdullah Wan Yusoff ${ }^{3}$ \\ ${ }^{1}$ Department of Crop Science, Faculty of Agriculture, University Putra Malaysia, 43400 Serdang, Selangor, Malaysia \\ ${ }^{2}$ Department of Agribusiness and Information System, Faculty of Agriculture, University Putra Malaysia, 43400 Serdang, \\ Selangor, Malaysia \\ ${ }^{3}$ Agro Technology Park, MARDI Cameron Highlands, Tanah Rata, 39007 Pahang, Malaysia
}

Correspondence should be addressed to Viyachai Taweesak; viyachai@yahoo.com

Received 6 June 2014; Accepted 22 October 2014; Published 16 November 2014

Academic Editor: Yanshan Cui

Copyright (C) 2014 Viyachai Taweesak et al. This is an open access article distributed under the Creative Commons Attribution License, which permits unrestricted use, distribution, and reproduction in any medium, provided the original work is properly cited.

Influences of irrigation frequency on the growth and flowering of chrysanthemum grown under restricted root volume were tested. Chrysanthemum cuttings (Chrysanthemum morifolium "Reagan White") were grown in seedling tray which contained coconut peat in volumes of 73 and $140 \mathrm{~cm}^{3}$. Plants were irrigated with drip irrigation at irrigation frequencies of $4(266 \mathrm{~mL}), 6(400 \mathrm{~mL})$, and $8(533 \mathrm{~mL})$ times/day to observe their growth and flowering performances. There was interaction between irrigation frequency and substrate volume on plant height of chrysanthemum. Plants grown in $140 \mathrm{~cm}^{3}$ substrates and irrigated 6 times/day produced the tallest plant of $109.25 \mathrm{~cm}$. Plants irrigated 6 and 8 times/day had significantly higher level of phosphorus content in their leaves than those plants irrigated 4 times/day. The total leaf area, number of internodes, leaf length, and leaf width of chrysanthemums grown in $140 \mathrm{~cm}^{3}$ substrate were significantly higher than those grown in $73 \mathrm{~cm}^{3}$ substrate. The numbers of flowers were affected by both irrigation frequencies and substrate volumes. Chrysanthemums irrigated 8 times/day had an average of 19.56 flowers while those irrigated 4 times/day had an average of 16.63 flowers. Increasing irrigation frequency can improve the growth and flowering of chrysanthemums in small substrate volumes.

\section{Introduction}

Many soilless systems have been studied for growing cut chrysanthemums. However, the production of chrysanthemum in soilless culture still has some problems to be resolved. Chrysanthemum grown in hydroponic systems was easily infected by Pythium $[1,2]$. Growing them in substrate had greater possibility for commercial production such as in sand culture [3]. However, using a high amount of substrate will increase production costs for replacing the substrate. Reducing substrate volume can be a possible solution for production in substrate culture [4]. To date, there have been few studies on the growth and flowering response of cut chrysanthemums in substrates of limited volume.
Restricted root volume will limit water and nutrient availability. Many studies have reported that higher frequencies of irrigation can improve plant growth in such limited substrates [5, 6]. High irrigation frequency can maintain moisture content at the root zone of plants grown in restricted substrate volume [7]. Moreover, high irrigation frequency can improve the uptake of nutrients through the replenishment of nutrients in the root zone and improve transport of nutrients by mass flow [8]. Röber and Hafez [9] found that chrysanthemum grown in substrates with high moisture produced high weights of shoots and flowers.

Chrysanthemums that were grown in rockwool and given nutrients 1 or 3 times/day produced satisfactory growth [10]. In the case of nutrient film technique, vegetative growth of 
chrysanthemums in substrates of volume less than $100 \mathrm{~mL}$ can be maintained by fertigation 8 times/day [11]. Gisleröd [12] found that irrigation frequency for growing cut chrysanthemum in substrate depended on the season and variety. The optimal frequency of irrigation should be tested for different substrates [13]. This experiment investigated the effects of irrigation frequency on the growth and flowering of cut chrysanthemum grown in restricted root volumes.

\section{Materials and Methods}

The experiment was conducted from March, 2014, to June, 2014, at Agro Technology Park, Malaysia Agriculture and Development Institute, Pahang, Malaysia, in a shade house with an average temperature of $25.8^{\circ} \mathrm{C}$ and relative humidity of $70.50 \%$. Rooted cuttings of Chrysanthemum morifolium "Reagan White" were grown in coconut peat at 73 and $140 \mathrm{~cm}^{3}$ volumes contained in seedling trays and a plant density of 64 plant $/ \mathrm{m}^{2}$. Plants were irrigated with a nutrient solution by drip irrigation at frequencies of $4(266 \mathrm{~mL}), 6(400 \mathrm{~mL})$, and $8(533 \mathrm{~mL})$ times/day. The nutrient solution used in the irrigation system from the first week to the seventh week included N 250, P 30, K 200, Ca 150, Mg 50, Fe 1.05, Mn 0.58, $\mathrm{Zn} \mathrm{0.35,} \mathrm{B} \mathrm{1,} \mathrm{Cu} \mathrm{0.05,} \mathrm{and} \mathrm{Mo} 0.05 \mathrm{mg} / \mathrm{L}$. After the seventh week and until harvest, the nutrient solution contained N 200, P 30, K 200, Ca 150, Mg 50, Fe 1.05, Mn 0.58, Zn 0.35, B 1, Cu 0.05 , and Mo $0.05 \mathrm{mg} / \mathrm{L}$. The $\mathrm{pH}$ of the nutrient solution was maintained between 5.5 and 6.5 and the electric conductivity (EC) was $1.3-1.5 \mathrm{mS} / \mathrm{cm}$. Night break was provided for 8 weeks from $11.00 \mathrm{pm}$. to $3.00 \mathrm{am}$.

Plant growth parameters such as plant height, stem diameter, leaf length, and leaf width were measured from two plant samples. Total leaf number and number of internodes were also counted. Root length was measured by using WinRHIZO, image analysis program (Regent instruments, Canada). Plant samples were dried in an oven at $70^{\circ} \mathrm{C}$ at least 48 hours, from which the dry weights of leaves, stems, roots, and flowers were determined. Leaf area was measured by Li-3100 area meter (LiCor Biosciences, USA). Leaf water potential was measured from fully expanded leaves by using a pressure chamber (Skye Instruments, UK) every two week and averaged means were used. Chlorophyll fluorescence was measured by Handy PEA (Hansatech Instruments, UK) to observe plant stress. Fully expanded leaf blades were darkened for 15 minutes by leaf clip. Sensor head was attached to the leaf clip, the shutter was opened and maximum quantum efficiency $(\mathrm{Fv} / \mathrm{Fm})$ was recorded.

Dry leaves at 14 weeks were ground and digested for nutrient analysis. Nitrogen $(\mathrm{N})$ and phosphorus $(\mathrm{P})$ were analyzed by autoanalyzer QuickChem 8000 (Lachat instruments, USA) and potassium (K), calcium (Ca), and magnesium (Mg) were analyzed using PerkinElmer 3110 atomic absorption spectrophotometer (PerkinElmer, USA).

At the point of harvesting, inflorescence diameter, number of flowers, number of petals, and flower diameter were observed. Lightness, chroma, and hue value of petal from three inflorescences were determined by CR-400 chroma meter (Konica Minolta, Japan). Stems of two flowers at a length of $35 \mathrm{~cm}$ were put in distilled water $300 \mathrm{~mL}$ at $25 \pm 1^{\circ} \mathrm{C}$,

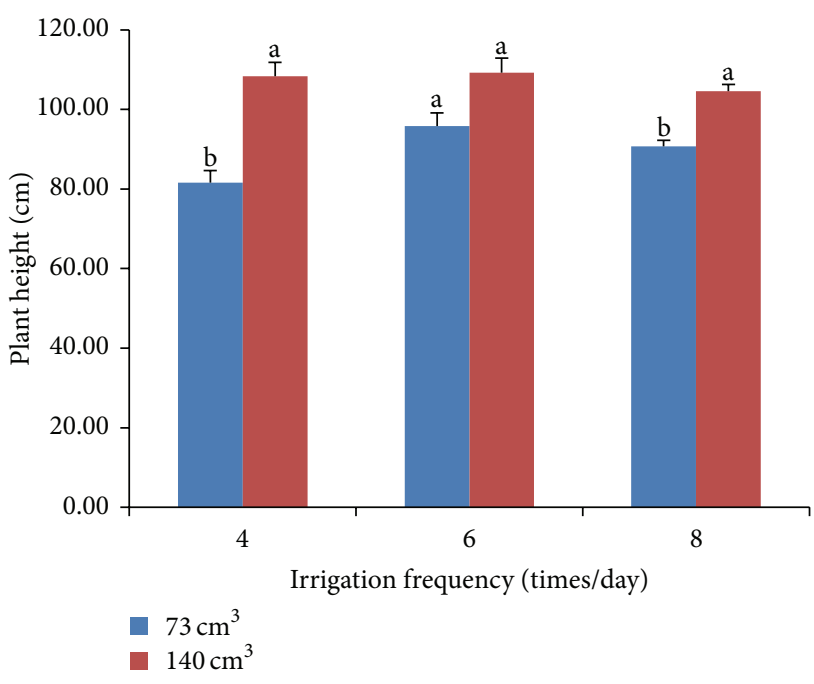

FIGURE 1: Interaction effects of irrigation frequencies and substrate volumes on plant height of chrysanthemum.

relative humidity 50-55\%, and light intensity $1.3 \mu \mathrm{mol} \mathrm{m}^{-2} \mathrm{~s}^{-1}$ for 10 hours per day to observe vase life.

Analysis of variance was calculated by SAS statistical software and means were compared by Tukey's test at $P<$ 0.05 .

\section{Results and Discussion}

There were significant interactions between irrigation frequency and substrate volume on plant height of chrysanthemum grown in substrate culture. As shown in Figure 1, greater substrate volume resulted in taller plant as compared to lower substrate volume at irrigation frequencies 4 and 8 time/day. The tallest plant of $109.25 \mathrm{~cm}$ was obtained from chrysanthemum grown in $140 \mathrm{~cm}^{3}$ irrigated 6 times/day. This corresponded with previous result with marigold by Latimer [14] who reported that increasing container volume resulted in higher plant heights. However, plant heights of chrysanthemum grown in all substrate volumes were lower than those grown in soil (data not shown). This may be due to the stress conditions present for plants grown under restricted root volumes.

Chlorophyll fluorescence efficiency or Fv/Fm values were not significantly different between substrate volumes or irrigation frequencies (Tables 1 and 2). Chrysanthemums grown in all volumes and at all irrigation frequencies had average Fv/Fm values that were lower than the average value of 0.84 of normal plants [15]. This result confirms that the plants experienced some stress. Chlorophyll content did not differ significantly by either variable. Both substrate volumes and irrigation frequencies influenced the water potential in the leaves, but those differences were not significant (Figure 2).

The substrate volumes had pronounced effects on growth characteristics (Table 3). Even stem diameters did not differ significantly between two substrate volumes. Chrysanthemum grown in substrate volumes of $140 \mathrm{~cm}^{3}$ had a larger number of internodes. Furthermore, total leaf area and 
TABLE 1: Effect of substrate volumes on chlorophyll fluorescence efficiency $(\mathrm{Fv} / \mathrm{Fm})$ and chlorophyll content.

\begin{tabular}{lcc}
\hline Substrate volume $\left(\mathrm{cm}^{3}\right)$ & 73 & 140 \\
\hline Fv/Fm & $0.68^{\mathrm{a}}$ & $0.73^{\mathrm{a}}$ \\
Chlorophyll content & $53.25^{\mathrm{a}}$ & $53.99^{\mathrm{a}}$ \\
\hline
\end{tabular}

Values in each column accompanied by different letters differ significantly at $P<0.05$ by Tukey's test.

TABLE 2: Effect of irrigation frequencies on chlorophyll fluorescence efficiency $(\mathrm{Fv} / \mathrm{Fm})$ and chlorophyll content.

\begin{tabular}{lccc}
\hline Irrigation frequency (times/day) & 4 & 6 & 8 \\
\hline Fv/Fm & $0.70^{\mathrm{a}}$ & $0.69^{\mathrm{a}}$ & $0.73^{\mathrm{a}}$ \\
Chlorophyll content & $53.21^{\mathrm{a}}$ & $54.12^{\mathrm{a}}$ & $53.53^{\mathrm{a}}$ \\
\hline
\end{tabular}

Values in each column accompanied by different letters differ significantly at $P<0.05$ by Tukey's test.

TABLE 3: Effect of substrate volumes on shoot growth of chrysanthemum.

\begin{tabular}{lcc}
\hline Substrate volume $\left(\mathrm{cm}^{3}\right)$ & 73 & 140 \\
\hline Stem diameter $(\mathrm{cm})$ & $0.57^{\mathrm{a}}$ & $0.58^{\mathrm{a}}$ \\
Number of internodes & $38.63^{\mathrm{b}}$ & $44.75^{\mathrm{a}}$ \\
Leaf area $\left(\mathrm{cm}^{2}\right)$ & $487.69^{\mathrm{b}}$ & $825.15^{\mathrm{a}}$ \\
Leaf number & $67.33^{\mathrm{b}}$ & $89.29^{\mathrm{a}}$ \\
Leaf length $(\mathrm{cm})$ & $9.22^{\mathrm{b}}$ & $11.38^{\mathrm{a}}$ \\
Leaf width $(\mathrm{cm})$ & $5.21^{\mathrm{b}}$ & $6.20^{\mathrm{a}}$ \\
\hline
\end{tabular}

Values in each column accompanied by different letters differ significantly at $P<0.05$ by Tukey's test.

number of leaves correlated to substrate volume. Leaf area of plants grown in $140 \mathrm{~cm}^{3}$ was higher than that in $73 \mathrm{~cm}^{3}$ by $69 \%$. This result was in agreement with other findings that found that increased substrate volume led to an increase in leaf area of chrysanthemum [11] and marigold [14]. Increasing substrate volume also increased leaf length and leaf width. Irrigation frequency, on the other hand, did not significantly affect shoot growth (Table 4). Differences between irrigation frequencies were not observed on stem diameter, number of internodes, leaf area, leaf number, leaf length, and leaf width. Substrate volume and irrigation frequency had an interaction effect on root length of chrysanthemum. However, there was no significant difference between each level of treatments alone but larger volumes tended to have longer root (Figure 3).

There was an interactive relationship between substrate volumes and irrigation frequencies upon the levels of nitrogen in leaves. When irrigated 4 times/day, nitrogen levels in smaller substrate volumes were higher than those in larger substrate volumes (Figure 4). When irrigated 6 and 8 times/day, there was no significant difference between the substrate volumes.

Substrate volume did not show significant differences for levels of phosphorus, potassium, calcium, and magnesium in the leaves of chrysanthemum (Table 5). But phosphorus level was influenced by irrigation frequency. Chrysanthemum irrigated 6 and 8 times/day had significantly higher

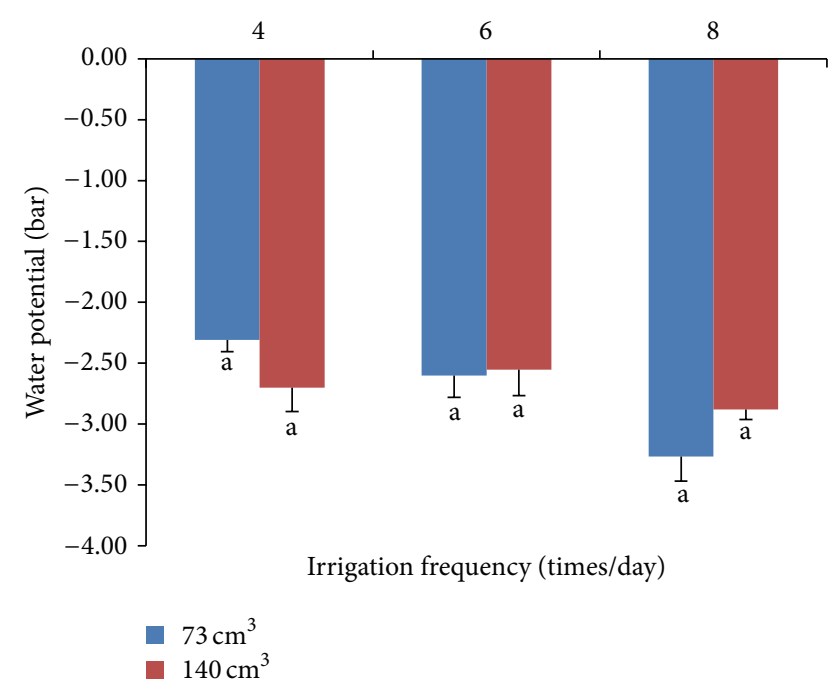

FIGURE 2: Interaction effects of irrigation frequencies and substrate volumes on water potential in leaves of chrysanthemum.

TABLE 4: Effect of irrigation frequencies on shoot growth of chrysanthemum.

\begin{tabular}{lccc}
\hline Irrigation frequency (times/day) & 4 & 6 & 8 \\
\hline Stem diameter $(\mathrm{cm})$ & $0.58^{\mathrm{a}}$ & $0.58^{\mathrm{a}}$ & $0.58^{\mathrm{a}}$ \\
Number of internodes & $40.19^{\mathrm{a}}$ & $44.25^{\mathrm{a}}$ & $40.63^{\mathrm{a}}$ \\
Leaf area $\left(\mathrm{cm}^{2}\right)$ & $577.28^{\mathrm{a}}$ & $693.84^{\mathrm{a}}$ & $698.14^{\mathrm{a}}$ \\
Leaf number & $67.69^{\mathrm{a}}$ & $86.81^{\mathrm{a}}$ & $80.44^{\mathrm{a}}$ \\
Leaf length $(\mathrm{cm})$ & $9.91^{\mathrm{a}}$ & $10.73^{\mathrm{a}}$ & $10.26^{\mathrm{a}}$ \\
Leaf width $(\mathrm{cm})$ & $5.56^{\mathrm{a}}$ & $5.96^{\mathrm{a}}$ & $5.59^{\mathrm{a}}$ \\
\hline
\end{tabular}

Values in each column accompanied by different letters differ significantly at $P<0.05$ by Tukey's test.

TABLE 5: Effect of substrate volumes on phosphorus, potassium, calcium, and magnesium level in leaves of chrysanthemum at 14 weeks after transplanting.

\begin{tabular}{lcc}
\hline Substrate volume $\left(\mathrm{cm}^{3}\right)$ & 73 & 140 \\
\hline $\mathrm{P}(\%)$ & $0.25^{\mathrm{a}}$ & $0.25^{\mathrm{a}}$ \\
$\mathrm{K}(\%)$ & $4.43^{\mathrm{a}}$ & $5.29^{\mathrm{a}}$ \\
$\mathrm{Ca}(\%)$ & $1.45^{\mathrm{a}}$ & $1.58^{\mathrm{a}}$ \\
$\mathrm{Mg}(\%)$ & $0.23^{\mathrm{a}}$ & $0.27^{\mathrm{a}}$ \\
\hline
\end{tabular}

Values in each column accompanied by different letters differ significantly at $P<0.05$ by Tukey's test.

phosphorus levels than when irrigated 4 times/day (Table 6). This result indicates that higher irrigation frequencies can improve availability of phosphorus [16]. On the other hand, potassium, calcium, and magnesium levels were not influenced by irrigation frequencies.

Substrate volumes and irrigation frequencies influenced dry weight partitioning between plant parts. Increasing substrate volume increased leaf, stem root, flower, and total dry weight significantly as shown in Table 7 . The increasing of root dry weight confirmed previous result by Goto et al. [11] who found that root dry weight of chrysanthemum increased 


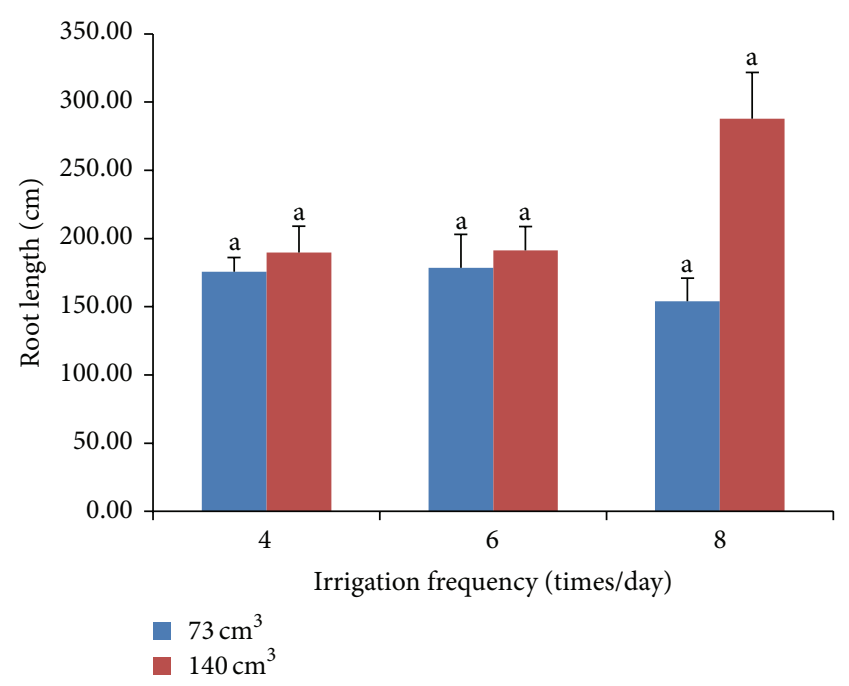

FIGURE 3: Interaction effects of substrate volumes and irrigation frequencies on root length of chrysanthemum.

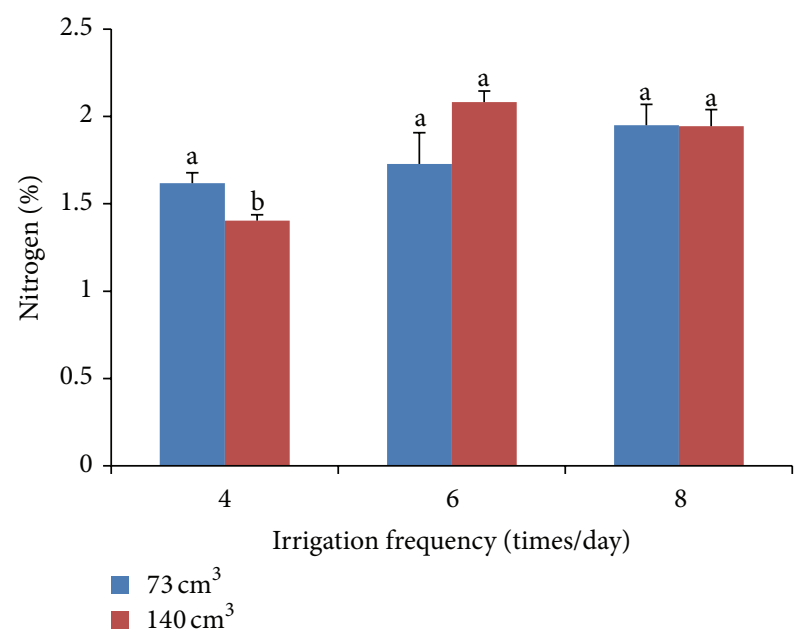

FIGURE 4: Interaction effects of substrate volumes and irrigation frequencies on nitrogen level of chrysanthemum.

TABLE 6: Effect of irrigation frequencies on phosphorus, potassium, calcium, and magnesium level in leaves of chrysanthemum at 14 weeks after transplanting.

\begin{tabular}{lccc}
\hline Irrigation frequency (times/day) & 4 & 6 & 8 \\
\hline $\mathrm{P}(\%)$ & $0.14^{\mathrm{b}}$ & $0.17^{\mathrm{a}}$ & $0.17^{\mathrm{a}}$ \\
$\mathrm{K}(\%)$ & $2.68^{\mathrm{a}}$ & $3.07^{\mathrm{a}}$ & $3.16^{\mathrm{a}}$ \\
$\mathrm{Ca}(\%)$ & $1.18^{\mathrm{a}}$ & $1.17^{\mathrm{a}}$ & $1.22^{\mathrm{a}}$ \\
$\mathrm{Mg}(\%)$ & $0.25^{\mathrm{a}}$ & $0.25^{\mathrm{a}}$ & $0.26^{\mathrm{a}}$ \\
\hline
\end{tabular}

Values in each column accompanied by different letters differ significantly at $P<0.05$ by Tukey's test.

with an increase of substrate volume. Total dry weight in $140 \mathrm{~cm}^{3}$ had total dry weight of $24.16 \mathrm{~g}$, which was higher than in $73 \mathrm{~cm}^{3}$ by $47.13 \%$.
TABLE 7: Effect of substrate volumes on leaf dry weight, stem dry weight, root dry weight, flower dry weight, and total dry weight.

\begin{tabular}{lcc}
\hline Substrate volume $\left(\mathrm{cm}^{3}\right)$ & 73 & 140 \\
\hline Leaf $(\mathrm{g})$ & $3.44^{\mathrm{b}}$ & $5.07^{\mathrm{a}}$ \\
Stem $(\mathrm{g})$ & $10.66^{\mathrm{b}}$ & $15.60^{\mathrm{a}}$ \\
Root $(\mathrm{g})$ & $0.40^{\mathrm{b}}$ & $0.67^{\mathrm{a}}$ \\
Flower $(\mathrm{g})$ & $1.92^{\mathrm{b}}$ & $2.82^{\mathrm{a}}$ \\
\hline Total $(\mathrm{g})$ & $16.42^{\mathrm{b}}$ & $24.16^{\mathrm{a}}$ \\
\hline
\end{tabular}

Values in each column accompanied by different letters differ significantly at $P<0.05$ by Tukey's test.

TABLE 8: Effect of irrigation frequencies on leaf dry weight, stem dry weight, root dry weight, flower dry weight, and total dry weight.

\begin{tabular}{lccc}
\hline Irrigation frequency (times/day) & 4 & 6 & 8 \\
\hline Leaf $(\mathrm{g})$ & $3.68^{\mathrm{b}}$ & $4.85^{\mathrm{a}}$ & $4.23^{\mathrm{a}}$ \\
Stem $(\mathrm{g})$ & $10.96^{\mathrm{b}}$ & $14.91^{\mathrm{a}}$ & $13.52^{\mathrm{a}}$ \\
Root $(\mathrm{g})$ & $0.50^{\mathrm{a}}$ & $0.58^{\mathrm{a}}$ & $0.53^{\mathrm{a}}$ \\
Flower $(\mathrm{g})$ & $2.02^{\mathrm{b}}$ & $2.29^{\mathrm{ab}}$ & $2.78^{\mathrm{a}}$ \\
\hline Total $(\mathrm{g})$ & $17.16^{\mathrm{b}}$ & $22.64^{\mathrm{a}}$ & $21.07^{\mathrm{a}}$ \\
\hline Values in each column accompanied by different letters differ significantly at \\
$P<0.05$ by Tukey's test.
\end{tabular}

Chrysanthemums irrigated 6 and 8 times/day had higher leaf dry weight, stem dry weight, and total dry weight than those irrigated 4 times/day as shown in Table 8. Schuch et al. [17] reported that chrysanthemums grown with high rates of irrigation produced higher stem dry weight than those obtained with lower irrigation frequency while root dry weight did not differ between irrigation frequencies. Chrysanthemum irrigated 8 times/day produced the highest flower dry weight. For total dry weight, plants irrigated 6 and 8 times/day were significantly higher than those irrigated 4 times/day by a factor of $32 \%$ and $23 \%$. Katsoulas et al. [18] also founded that increasing irrigation frequency increased total dry mass of rose.

The number of flowers was affected by both substrate volumes and irrigation frequencies (Tables 9 and 10). When grown in $140 \mathrm{~cm}^{3}$, there were $33 \%$ more flowers than in $73 \mathrm{~cm}^{3}$. Irrigation 8 times/day produced the highest number of flowers, an average of 20.44. However, inflorescence diameter, flower diameter, number of petals, flower color, and vase life were not significantly influenced by either irrigation frequency or substrate volume. This outcome accorded with the studied one in gerbera, in which flower diameter was not influenced by irrigation frequency [19]. Carvalho et al. [20] noted that flower size of chrysanthemum was mainly influenced by genetic inheritance.

\section{Conclusions}

Results from this experiment demonstrated that irrigation frequencies of 6 and 8 times/day can improve plant growth and flowering characteristics such as plant dry weight and number of flowers of chrysanthemum plants grown under restricted root conditions. This may be attributable to a 
TABLE 9: Effect of substrate volumes on flowering characteristics of chrysanthemum.

\begin{tabular}{lcc}
\hline Substrate volume $\left(\mathrm{cm}^{3}\right)$ & 73 & 140 \\
\hline Inflorescence diameter $(\mathrm{cm})$ & $12.57^{\mathrm{a}}$ & $13.52^{\mathrm{a}}$ \\
Number of flowers & $16.21^{\mathrm{b}}$ & $21.54^{\mathrm{a}}$ \\
Flower diameter $(\mathrm{cm})$ & $6.37^{\mathrm{a}}$ & $6.06^{\mathrm{a}}$ \\
Number of petals & $25.50^{\mathrm{a}}$ & $25.35^{\mathrm{a}}$ \\
Flower color & & \\
$\quad$ & $75.92^{\mathrm{a}}$ & $77.05^{\mathrm{a}}$ \\
$\quad$ Lightness & $2.93^{\mathrm{a}}$ & $2.96^{\mathrm{a}}$ \\
Chroma & $81.33^{\mathrm{a}}$ & $83.84^{\mathrm{a}}$ \\
$\quad$ Hue & $20.96^{\mathrm{a}}$ & $21.21^{\mathrm{a}}$ \\
Vase life (days) &
\end{tabular}

Values in each column accompanied by different letters differ significantly at $P<0.05$ by Tukey's test.

TABLE 10: Effect of irrigation frequencies on flowering characteristics of chrysanthemum.

\begin{tabular}{lccc}
\hline Irrigation frequency (times/day) & 4 & 6 & 8 \\
\hline Inflorescence diameter (cm) & $11.92^{\mathrm{a}}$ & $13.59^{\mathrm{a}}$ & $13.62^{\mathrm{a}}$ \\
Number of flowers & $16.63^{\mathrm{b}}$ & $19.56^{\mathrm{ab}}$ & $20.44^{\mathrm{a}}$ \\
Flower diameter (cm) & $5.71^{\mathrm{a}}$ & $6.19^{\mathrm{a}}$ & $6.76^{\mathrm{a}}$ \\
Number of petals & $26.31^{\mathrm{a}}$ & $25.33^{\mathrm{a}}$ & $24.63^{\mathrm{a}}$ \\
Flower color & & & \\
$\quad$ Lightness & $70.76^{\mathrm{a}}$ & $81.40^{\mathrm{a}}$ & $77.30^{\mathrm{a}}$ \\
$\quad$ Chroma & $2.67^{\mathrm{a}}$ & $3.17^{\mathrm{a}}$ & $3.00^{\mathrm{a}}$ \\
$\quad$ Hue & $78.76^{\mathrm{a}}$ & $86.66^{\mathrm{a}}$ & $82.33^{\mathrm{a}}$ \\
Vase life (days) & $21.19^{\mathrm{a}}$ & $20.81^{\mathrm{a}}$ & $21.25^{\mathrm{a}}$ \\
\hline
\end{tabular}

Values in each column accompanied by different letters differ significantly at $P<0.05$ by Tukey's test.

higher availability of nitrogen and phosphorus. We conclude that for cultivation efficiency, an irrigation frequency of 6 times/day can be suggested for growing chrysanthemums under restricted root volume.

However, further studies are required to confirm that increasing the irrigation frequency can improve plant growth under restricted conditions.

\section{Conflict of Interests}

The authors declare that there is no conflict of interests regarding the publication of this paper.

\section{Acknowledgments}

This research was supported by the Southeast Asian Regional Center for Graduate Study and Research in Agriculture (SEARCA) and Malaysian Agricultural Research and Development Institute (MARDI).

\section{References}

[1] A. Liptay and J. C. Tu, "Hydroponic chrysanthemum production: cultural and pathological issues," Communications in Agricultural and Applied Biological Sciences, vol. 68, no. 4, pp. 613-618, 2003.
[2] W. Liu, J. C. Sutton, B. Grodzinski, J. W. Kloepper, and M. S. Reddy, "Biological control of pythium root rot of chrysanthemum in small-scale hydroponic units," Phytoparasitica, vol. 35, no. 2, pp. 159-178, 2007.

[3] D. P. Wilson and A. R. Finlay, "Hydroponic system for the production of all-year-round chrysanthemum," Acta Horticulturae, vol. 40, pp. 185-192, 1995.

[4] F. Buwalda, R. Baas, and P. A. van Weel, "A soilless ebb-and-flow system for all year round chrysanthemums," Acta Horticulturae, vol. 361, pp. 123-132, 1986-1994.

[5] R. C. D. M. Pires, P. R. Furlani, R. V. Ribeiro et al., "Irrigation frequency and substrate volume effects in the growth and yield of tomato plants under greenhouse conditions," Scientia Agricola, vol. 68, no. 4, pp. 400-405, 2011.

[6] C. F. Scagel, G. Bi, L. H. Fuchigami, and R. P. Regan, "Irrigation frequency alters nutrient uptake in container-grown rhododendron plants grown with different rates of nitrogen," HortScience, vol. 47, no. 2, pp. 189-197, 2012.

[7] G. Gizas and D. Savvas, "Particle size and hydraulic properties of pumice affect growth and yield of greenhouse crops in soilless culture," HortScience, vol. 42, no. 5, pp. 1274-1280, 2007.

[8] A. Silber, G. Xu, I. Levkovitch, S. Soriano, A. Bilu, and R. Wallach, "High fertigation frequency: the effects on uptake of nutrients, water and plant growth," Plant and Soil, vol. 253, no. 2, pp. 467-477, 2003.

[9] R. Röber and M. Hafez, "The influence of different water supply upon the growth of chrysanthemum," Acta Horticulturae, vol. 125 , pp. 69-78, 1982.

[10] V. N. Paul and F. C. William, "Physical analysis of rockwool slabs and effects of fiber orientation, irrigation frequency and propagation technique on chrysanthemum production," Journal of Plant Nutrition, vol. 14, no. 8, pp. 853-866, 1991.

[11] T. Goto, N. Takaya, N. Yoshioka, Y. Yoshida, Y. Kageyama, and K. Konishi, "Effects of water and nutrient stresses on reduction of vegetative growth in chrysanthemum grown under restricted root zone volume," Journal of the Japanese Society for Horticultural Science, vol. 70, no. 6, pp. 760-766, 2001.

[12] H. R. Gisleröd, "Effects of watering frequency on growth of cut chrysanthemums," Acta Horticulturae, vol. 221, pp. 327-334, 1988.

[13] M. Raviv, R. Wallach, A. Silber, S. Medina, and A. Krasnovsky, "The effect of hydraulic characteristics of volcanic materials on yield of roses grown in soilless culture," Journal of the American Society for Horticultural Science, vol. 124, no. 2, pp. 205-209, 1999.

[14] J. G. Latimer, "Container size and shape influence growth and landscape performance of marigold seedlings," HortScience, vol. 26, no. 2, pp. 124-126, 1991.

[15] K. Maxwell and G. N. Johnson, "Chlorophyll fluorescence-a practical guide," Journal of Experimental Botany, vol. 51, no. 345, pp. 659-668, 2000.

[16] G. Xu, I. Levkovitch, S. Soriano, R. Wallach, and A. Silber, "Integrated effect of irrigation frequency and phosphorus level on lettuce: P uptake, root growth and yield," Plant and Soil, vol. 263, no. 1, pp. 297-309, 2004.

[17] U. K. Schuch, R. A. Redak, and J. A. Bethke, "Cultivar, fertilizer, and irrigation affect vegetative growth and susceptibility of chrysanthemum to western flower thrips," Journal of the American Society for Horticultural Science, vol. 123, no. 4, pp. 727-733, 1998. 
[18] N. Katsoulas, C. Kittas, G. Dimokas, and C. Lykas, "Effect of irrigation frequency on rose flower production and quality," Biosystems Engineering, vol. 93, no. 2, pp. 237-244, 2006.

[19] I. Tsirogiannis, N. Katsoulas, and C. Kittas, "Effect of irrigation scheduling on gerbera flower yield and quality," HortScience, vol. 45 , no. 2, pp. 265-270, 2010.

[20] S. M. P. Carvalho, E. Heuvelink, J. Harbinson, and O. van Kooten, "Role of sink-source relationships in chrysanthemum flower size and total biomass production," Physiologia Plantarum, vol. 128, no. 2, pp. 263-273, 2006. 


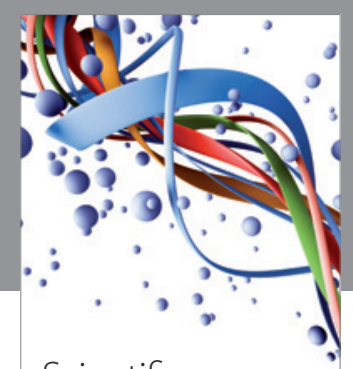

Scientifica
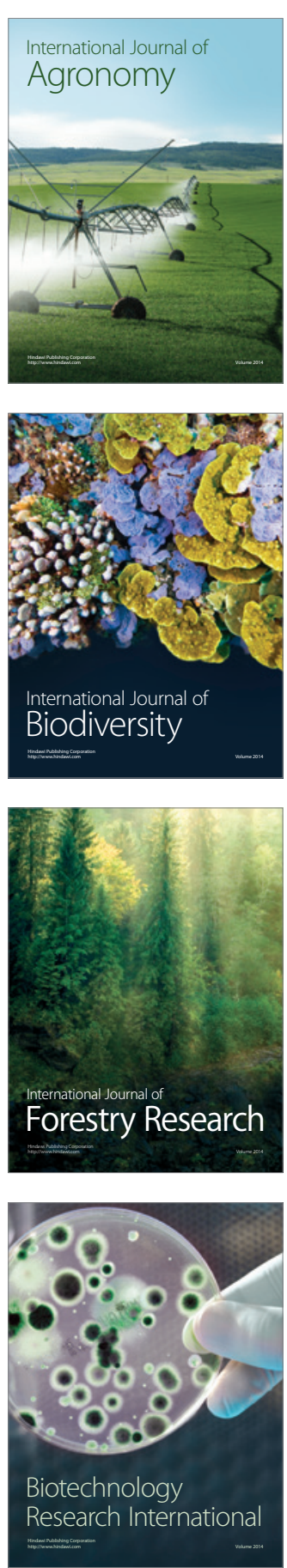
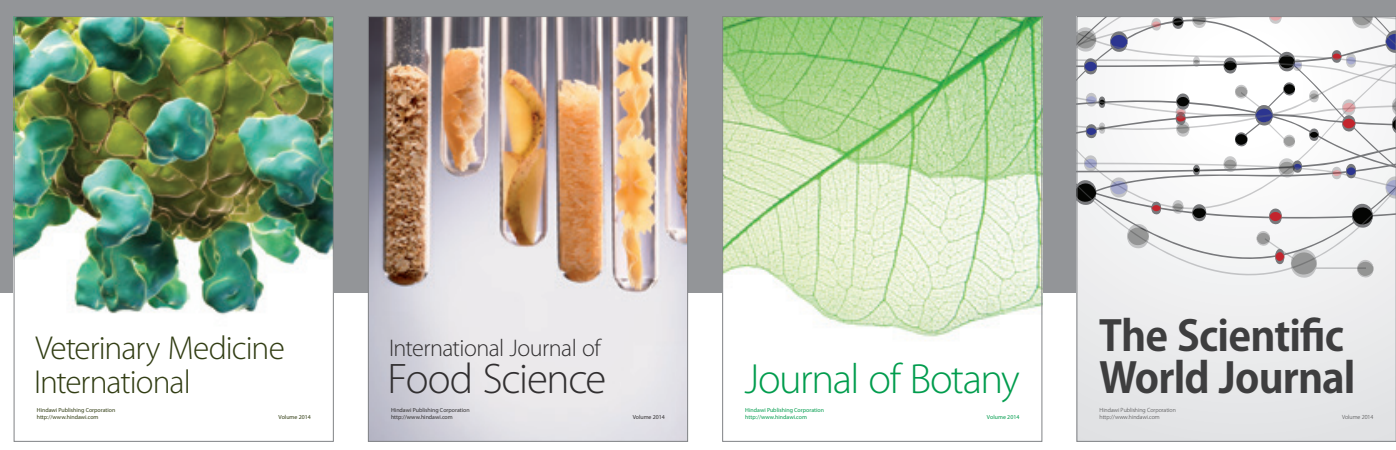

The Scientific World Journal
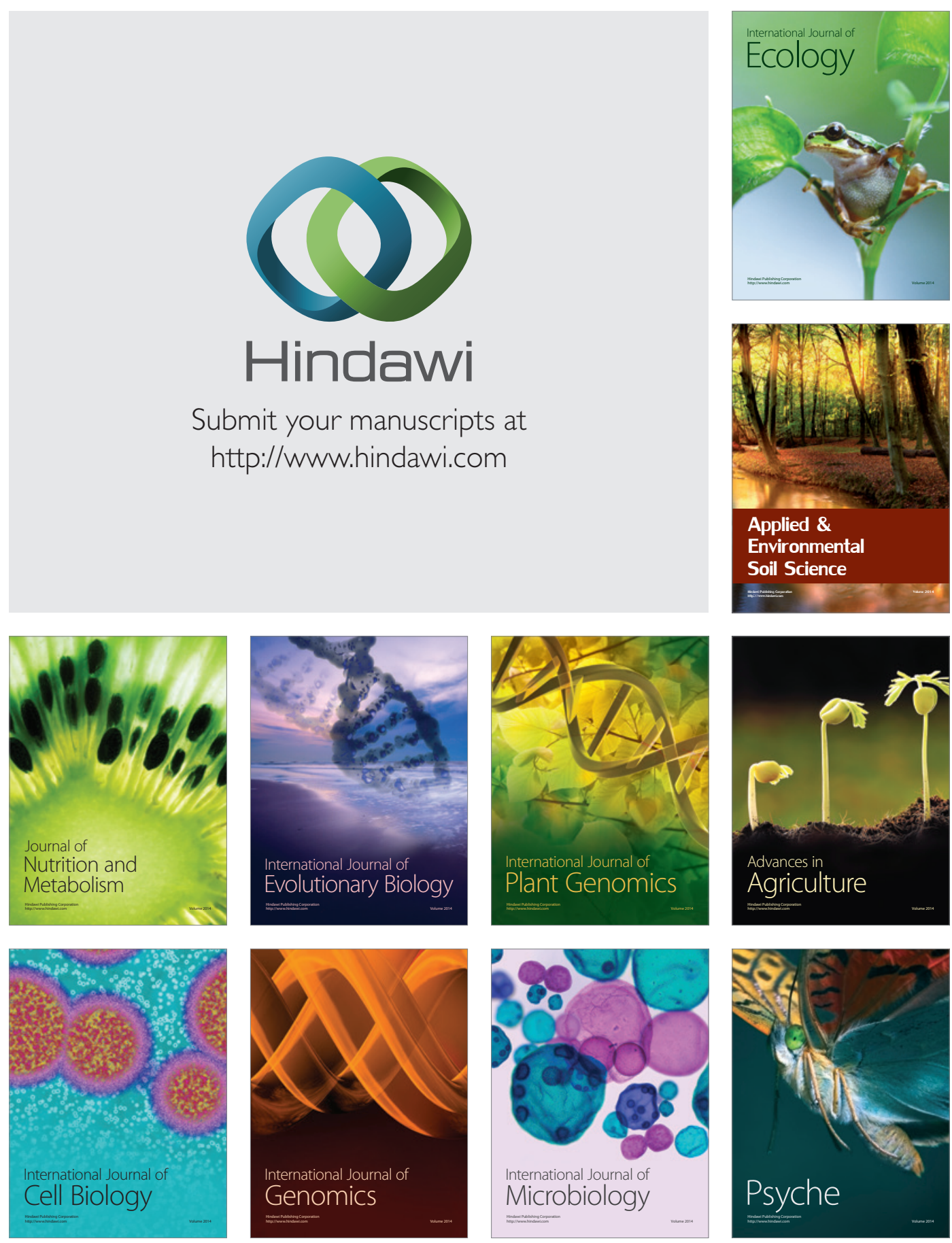